\title{
A Comparison of Substance Abuse and Mental Illness in Male Offenders in Jamaica and England and Wales
}

\author{
CA Sewell ${ }^{1}$, FW Hickling ${ }^{2}$, WD Abel ${ }^{1}, \mathrm{~S} \mathrm{Smith}^{3}$, V Paisley ${ }^{4}$, J Martin ${ }^{1}$, J Shaw ${ }^{5}$
}

\begin{abstract}
Background: The present study sought to determine the prevalence of substance abuse, mental illness, sociodemographics and clinical characteristics of mentally ill offenders. These data were compared to data from the prison population in the United Kingdom.

Method: This is a cross-sectional study of male, mentally ill offenders in two prisons in Jamaica, and four prisons in England and Wales. For the Jamaican sample, a psychopathology and forensic survey instrument was developed by the research personnel to extract specific information from the diagnostic interview. Data extraction was done over a one-year period. For the England and Wales sample, the participants were interviewed and assessed using various structured instruments.

Results: The results indicate that approximately $18 \%$ of persons within the Jamaican prison population under study had a mental illness. Of this number, 57\% of these persons had been previously diagnosed with a Diagnostic and Statistical Manual of Mental Disorders, fourth edition, text revision (DSM IVTR) Axis 1 disorder. Substance abuse was the most frequently diagnosed DSM-IV Axis I disorder within both populations. The prevalence of mental illness found in the Jamaican prison population was approximately four times greater than the rate in the comparison population of England and Wales.

Conclusions: There was an over-representation of mentally ill offenders in the Jamaican prison population. This is most likely linked to the lack of appropriate diversion programmes and a forensic mental hospital in Jamaica.
\end{abstract}

Keywords: Male offenders, substance abuse, mental illness

WIMJ Open 2015; 2 (1): 36

\section{INTRODUCTION}

Globally, the prison population has been estimated at nine million persons, with males disproportionately represented, accounting for approximately $80 \%$ of this population $(1,2)$. This population presents with behavioural and psychological issues $(3,4)$. Extant research indicates that at least half of a prison population meets the criteria for a substance abuse or dependence problem (5) and roughly $4 \%$ of the prison population is likely to have a psychotic disorder and $10 \%$ a major depressive disorder (2).

Research pellucidly reveals an association between having mental disorders and higher rates of conviction (6), and that mentally disordered persons who commit violent offences are more likely to be males, of a young age, severely ill, resistant to treatment, substance abusers and have a prior history of committing a violent criminal offence (7). Not-

From: ${ }^{1}$ Department of Community Health and Psychiatry, The University of the West Indies, Kingston 7, Jamaica, ${ }^{2}$ Caribbean Institute of Mental Health and Substance Abuse (CARIMENSA), The University of the West Indies, Kingston 7, Jamaica, ${ }^{3}$ Forensic Mental Health Teaching Unit, Institute of Psychiatry, Kings College, London, England, ${ }^{4}$ Private practice, Kingston, Jamaica and ${ }^{5}$ University of Manchester, Manchester, England.

Correspondence: Dr CA Sewell, Department of Community Health and Psychiatry, The University of the West Indies, Kingston 7, Jamaica, West Indies. E-mail: clansewell@yahoo.com withstanding, the proportion of violence committed by mentally disordered persons is relatively small and purported to be qualitatively proportional to violent crimes committed by the general population (8).

Approximately $25 \%$ of mental illness among prisoners goes unrecognized (9). Additionally, persons may develop mental illness while incarcerated. Appropriate identification and placement of mentally ill persons is important in the treatment, follow-up and rehabilitation of these individuals $(10,11)$.

Furthermore, many low- and middle-income countries do not have well-developed, formal prison healthcare services (12). In jurisdictions with well-developed mental healthcare for mentally disordered offenders, there are fewer offenders with severe mental illness remaining in prison as these offenders are diverted to hospital.

There is a dearth of data available on mentally ill offenders in Jamaica. Accordingly, in this study we sought to determine the prevalence of mental illness and sociodemographic and clinical characteristics of mentally ill offenders. We also compared the data with those on the prison population in the United Kingdom. 


\section{SUBJECTS AND METHOD}

This is a cross-sectional study of male, mentally ill offenders in two prison population settings: Jamaica, and England and Wales. The study population consisted of male offenders, age 18 years and older.

\section{Jamaica}

In Jamaica, the Tower Street and St Catherine Adult Correctional Centres are the two major facilities for imprisonment of male offenders and were included in the study for this reason. Of the total population $(n=2969)$, the sample consisted of all the inmates who had been assessed by the study personnel as having a Diagnostic and Statistical Manual of Mental Disorders, fourth edition (DSM-IV) Axis I diagnosis $(\mathrm{n}=525)$.

\section{England and Wales}

In England and Wales, Her Majesty's Prison Service (HMPS) Belmarsh, Forest Bank, Manchester and Wymott prisons were included in the study. The sample $(n=130)$ was derived from data collected as part of the evaluation of prison mental health in-reach services by Shaw and Humber (13), which was conducted on the male offender populations ( $\mathrm{n}=$ 4204).

Persons assessed in Jamaican prisons were identified as Group 1 and persons assessed in English and Welsh prisons identified as Group 2. Persons were included in either group if they were male offenders who had undergone a psychiatric assessment and found to have a DSM IV Axis I disorder. Persons were excluded if they were found not to have a DSM-IV Axis I disorder.

Formal psychiatric assessments were conducted with the sample in Group 1 by the study personnel who consisted of two resident psychiatrists. The psychiatric evaluations, including past medical and forensic history and mental status examination, were used to determine the presence of a DSMIV Axis I diagnosis. A psychopathology and forensic survey instrument was developed by the research personnel to extract specific information from the diagnostic interview. Permission was granted by the Department of Correctional Services, Jamaica, for the recording of the relevant sociodemographic, forensic and psychopathology characteristics of the male criminal offenders, including diagnoses and treatment, family history and history of substance use. Data extraction was done over a one-year period (2006 to 2007).

The sample in Group 2 was obtained by researchers from the Prison Health Research Network, lead by Professor Jenny Shaw at the University of Manchester with collaboration from the Institute of Psychiatry and the Universities of Southampton and Sheffield. The participants were interviewed and assessed using various structured instruments including the Brief Psychiatric Rating Scale (BPRS), Schedule for Affective Disorders and Schizophrenia (SADS), General Health Questionnaire (GHQ), Michigan Alcohol Screening Test (MAST), Drug Abuse Screening Test
(DAST), and Structured Clinical Interview for DSM Disorders (SCID). Data were collected over a three-year period. The relevant sociodemographic, psychopathology and forensic information was extracted from these data sources to facilitate the examination of the characteristics of the two study groups.

All data analysis was done using the Statistical Package for Social Sciences (SPSS), version 11.0. All statistical tests were considered significant at the $p<0.05$ level.

\section{RESULTS}

Of the total population within the two institutions in Jamaica $(\mathrm{n}=2969), 525(17.7 \%)$ male adult offenders with a significant DSM-IV Axis I pathology were identified; 259 (49.3\% of the mentally ill sample) were housed at the St Catherine Adult Correctional Centre (SCACC) and 266 (50.7\%) at the Tower Street Adult Correctional Centre (TSACC). Within the total population garnered from England and Wales $(\mathrm{n}=$ 4202), there were 130 (3.09\%) male adult offenders with a significant DSM-IV Axis I pathology. They were being held at HMPS Belmarsh (26; 20\%), Forest Bank (37, 28.5\%), Manchester (44, 33.8\%) and Wymott (23, 17.7\%).

The Jamaican sample represented $20 \%$ and $15 \%$ of the offender population at SCACC and TSACC, respectively, which was far greater than the sample taken from England and Wales, which constituted between $2.2 \%$ and $4.3 \%$ of the offender population of HMPS in the study.

\section{Demographic characteristics}

The majority $(89.7 \%)$ of the mentally ill offenders in the Jamaican sample were young to middle-aged adults, with $31.2 \%$ in the 18 to 29 -year age range and just over half (58.5\%) between the ages 30 and 49 years. This age configuration was parallel to the pattern found in the sample from England and Wales $(p>0.05)$. Persons from the Jamaican group were, however, more likely to be single $(92.2 \%)$ and to report being employed prior to their incarceration (89\%) than those from the England and Wales group [76.9\% and 25.4\%, respectively; $p<0.05$ ] (Table 1 ).

\section{Substance abuse}

Substance abuse was the most frequently diagnosed DSM-IV Axis I disorder within both populations, and also presented more frequently as a co-morbid diagnosis with psychotic disorders in Jamaica and with mood/anxiety disorders in England and Wales. Psychotic disorders were significantly more prevalent in the Jamaican population, with just above half of the mentally ill prisoners having a diagnosis that included a psychotic disorder (56.6\%), and $16.8 \%$ of these having psychotic disorders as the only diagnosis. Comparatively, prisoners in England and Wales were significantly more likely to have co-morbid disorders or a single diagnosis of mood disorder (Table 2). 
Table 1: Demographic and criminological characteristics of mentally ill prison populations

\begin{tabular}{lcccc}
\hline & $\begin{array}{c}\text { Jamaica } \\
\mathbf{n}(\mathbf{\%})\end{array}$ & $\begin{array}{c}\text { England and Wales } \\
\mathbf{n}(\mathbf{\%})\end{array}$ & $\chi^{\mathbf{2}}$ & $\boldsymbol{p}$-value \\
\hline Age range (years) & & & 1.005 & 0.61 \\
$18-29$ & $164(31.2)$ & $46(35.4)$ & & \\
$30-49$ & $307(58.5)$ & $73(56.2)$ & & \\
$50+$ & $54(10.3)$ & $11(8.5)$ & & \\
Mean age & $35.64 \pm 10.91$ & $34.60 \pm 9.79$ & 25.131 & $<0.001$ \\
Marital status & & & & \\
Married/Co-habiting & $41(7.8)$ & $30(23.1)$ & & \\
Single & $484(92.2)$ & $100(76.9)$ & 233.086 & $<0.001$ \\
Employment status & & & & \\
Employed & $467(89.0)$ & $33(25.4)$ & & \\
Unemployed & $58(11.0)$ & $97(74.6)$ & & \\
Type of offence & & & 119.654 & $<0.001$ \\
Violent & $390(74.3)$ & $43(33.1)$ & & \\
Property & $83(15.8)$ & $50(38.5)$ & & \\
Drug & $11(2.1)$ & $1(0.8)$ & & \\
Public order & $3(0.6)$ & $18(13.9)$ & & \\
Sexual & $38(7.2)$ & $18(13.8)$ & & \\
\hline
\end{tabular}

Regardless of diagnosis, Jamaican prisoners were more likely to be incarcerated for violent crimes (74.3\%), whereas offenders in England and Wales were almost equally likely to commit violent crimes (33.1\%) and property crimes [38.5\%] (Table 1). Inmates diagnosed with substance abuse disorders alone or as a co-morbid diagnosis were generally the most likely to commit either type of crime in both populations. However, in the Jamaican population, persons were more likely to be diagnosed with co-morbid substance abuse and psychotic disorders, whereas in England and Wales, they were more likely to have co-morbid substance abuse and $\mathrm{mood} /$ anxiety disorders.

Despite the large percentage of prisoners in both populations being diagnosed with a substance abuse disorder, none in Jamaica and only $11.3 \%$ in England and Wales were being treated pharmacologically. The focus of treatment seemed to have been on the more enduring Axis I disorders; almost all persons (99\%) in the Jamaican population diagnosed with a psychotic disorder were being treated with

Table 2: Prevalence of Diagnostic and Statistical Manual of Mental Disorders, fourth edition (DSM-IV) Axis I disorders

\begin{tabular}{lcc}
\hline Disorder & \multicolumn{2}{c}{ Country } \\
& $\begin{array}{c}\text { Jamaica } \\
\text { n (\%) }\end{array}$ & $\begin{array}{c}\text { England and Wales } \\
\text { n (\%) }\end{array}$ \\
\hline Primary diagnosis & & \\
Psychotic disorder & $88(16.8)$ & $3(2.3)$ \\
Mood/anxiety disorder & $7(1.3)$ & $10(7.7)$ \\
Substance abuse & $204(38.9)$ & $42(32.3)$ \\
Co-morbid diagnoses & & \\
Substance abuse and psychotic disorder & $209(39.8)$ & $8(6.2)$ \\
Substance abuse and mood/anxiety disorder & $13(2.5)$ & $41(31.5)$ \\
Psychotic and mood/anxiety disorder & $0(0)$ & $8(6.2)$ \\
Substance abuse and psychotic disorder & $0(0)$ & $18(13.8)$ \\
and mood/anxiety disorder & & \\
\hline
\end{tabular}

$\chi^{2}=281.459(7) ; p=0.000$

\section{Mental health issues}

Just under half $(43.2 \%)$ of the Jamaican prisoners had no previous contact with mental health services and approximately $19 \%$ had first contact over 15 years prior to the study date. Conversely, the majority of prisoners in England and Wales had some contact with mental health services prior to their convictions $(93.8 \%)$, with most persons (80\%) having first contact less than nine years prior to their involvement in the study. Despite more than half of the prisoners in both prison populations having been previously diagnosed with a DSM-IV Axis I disorder (56.8\% Jamaica and 67.7\% England and Wales; $\left.\chi^{2}=-0.114 ; p=0.004\right)$, the majority of mentally ill prisoners had no previous psychiatric hospital admissions (82.9\% of Jamaican population and $88.5 \%$ of English and Welsh population; $p>0.05)$. antipsychotic medication, and all persons diagnosed with a mood or anxiety disorder were being treated with either antidepressants or mood stabilizers. In comparison, pharmacological interventions were used less in England and Wales where $60 \%$ of persons who had a psychotic disorder were being treated with antipsychotic medications, and 50\% of persons with mood or anxiety disorders were being treated with antidepressants, mood stabilizers or benzodiazepines.

\section{Offences}

There were significant differences in the types of offences committed by the two groups. Jamaican prisoners were just over two times more likely to be incarcerated for violent crimes $(74.3 \%)$ and drug offences $(2.1 \%)$ than persons from England and Wales (33.1\% and $0.8 \%$, respectively). On the 
other hand, persons from England and Wales were approximately twice more likely to be convicted for property crimes (38.5\%), sexual offences (13.8\%), and public order and other offences (13.9\%) as compared to Jamaican offenders (15.8\%, $7.2 \%$ and $0.6 \%$, respectively) [Table 1]. Most of the Jamaican men $(71 \%)$ had no previous convictions and this is counter to those from England and Wales where only 23.1\% had no prior convictions. Within this group, $10.8 \%$ had one prior conviction and $58.5 \%$ had two or more prior convictions $\left(\chi^{2}=207.373 ; p=0.000\right)$.

\section{Period of incarceration}

There was also a significant difference in the length of incarceration of the prisoners in the two groups $\left(\chi^{2}=\right.$ 131.266; $p=0.000$ ). In the Jamaican sample, the length of stay was almost equally distributed across the years: less than one year, $20.6 \%$; one to three years, $29.7 \%$; four to six years, $22.7 \%$ and seven years and over, $27 \%$. In comparison, none of the offenders in the group from England and Wales were incarcerated for over three years: $63.1 \%$ for less than a year and $36.9 \%$ for one to three years.

\section{DISCUSSION}

The results indicate that approximately $18 \%$ of persons within the Jamaican prison population under study had a mental illness. Approximately half (58\%) of these persons were aged 30-49 years, had been accused of violent crimes $(74.3 \%)$ and had no prior convictions. Of the $57 \%$ of these persons who had been previously formally diagnosed with a DSM-IV Axis 1 diagnosis, over $80 \%$ of these persons had never been hospitalized and were not exposed to continuous care, though $19 \%$ of them had their point of first contact over 15 years ago.

Furthermore, the prevalence of mental illness found in the Jamaican prison populations was approximately four times greater than the rate in the comparison population (England and Wales), indicating an over-representation of mentally ill persons in Jamaican prisons.

This suggests a shortfall in the community mental health service provision and tracking of mentally ill persons within the communities, as well as lack of social support to assist in seeking treatment for these persons. Given the progression of untreated or inadequately treated mental illness to criminality, it is possible that prior diagnosis and treatment would have reduced the number of persons who would have gone on to offend.

The sample of Jamaican offenders tended to have a longer length of incarceration and no previous convictions, with most being incarcerated for over four years at the time of the study as compared to the offenders in England and Wales who stayed no longer than three years. It is likely that the jail-diversion programmes in England and Wales appropriately channel the mentally ill to psychiatric institutions, which may explain why none of these inmates remain in prison for more than three years regardless of the type of crime committed.

The absence of a forensic mental health service/ hospital and effective public policy diverting the mentally ill to treatment, has meant that seriously mentally ill men are placed in prisons for significantly longer periods of time. Thus, although almost all prisoners in Jamaica receive psychopharmacological treatment, the prisons do not provide adequate psychiatric/rehabilitative care, which inhibits the potential for recovery. As a result, the morbidity associated with these disorders remains high, with many of the offenders being incarcerated for the majority of their lives. Furthermore, the backlog of criminal cases in the Jamaican justice system has put the "unfit to plead" mentally ill offenders at a disadvantage as their cases are not given priority status and they often wait for years after becoming fit before they are returned to court.

High rates of substance use disorders have been consistently found in studies conducted in correctional settings. The results obtained in this study reflect that approximately a third of the persons sampled had a substance use disorder. However, a relatively smaller number of these offenders were incarcerated for a drug offence. This suggests that most of the substance users were not necessarily involved in the trading of substances. It is quite likely that in a number of the cases identified, the use of a substance impacted on the commission of an offence and also on the presence of psychopathology.

\section{Limitations}

There are inherent limitations in selecting study groups from different prisons or different jurisdictions and comparing these disparate groups. The culture and environmental setting of the prison may contribute to the results obtained. The Jamaican sample was derived from maximum security facilities, whereas the prisons in England and Wales were from category $\mathrm{A}, \mathrm{B}$ and $\mathrm{C}$ prisons. The accommodations provided to inmates and the extent of factors, such as overcrowding, may promote the development of particular psychopathology occurring among the offenders. Despite the limitations present in this study, the findings reinforce the need for greater resources to be allocated to the management of mentally ill offenders as well as a restructuring of the legal framework and the forensic mental health services required to adequately address their needs.

\section{CONCLUSION}

Preliminary as these findings may be, they have yielded useful information with implications for policy and service development. First, in the Jamaican context, there is very little screening for substance use disorders at reception into prison. While drug courts have been established to divert persons from the prisons, a number of these individuals do end up being incarcerated. Therefore, the correctional ser- 
vices would benefit from the provision of substance use treatment programmes within the prisons and for probation and aftercare services. Unfortunately, being incarcerated may provide the only opportunity for some offenders to access substance abuse treatment.

Second, in the absence of forensic facilities, it may be beneficial to establish a relationship between the prisons and mental health facilities such as the community mental health services which can be utilized to provide outsourced care. Third, policies should address the diversion of persons with mental illness, committing minor crimes, to the appropriate treatment rather than containing them in a prison facility. Fourth, an increase in community mental health services that screen, track and monitor persons with mental illness and those re-entering society might ensure that such persons are provided with adequate healthcare to reduce the likelihood of engaging in criminal activity.

\section{REFERENCES}

1. Warmsley R. Prison health care and the extent of prison overcrowding. Int J Prisoner Health 2005; 1: 9-12.

2. Fazel S, Danesh J. Serious mental disorder in 23000 prisoners: a systematic review of 62 surveys. Lancet 2002; 359: 545-50.

3. Mumola CJ. Substance abuse and treatment, state and federal prisoners, 1997. Washington, DC: Bureau of Justice Statistics; 1999.

4. Singleton N, Farrell M, Meltzer H. Substance misuse among prisoners in England and Wales. Int Rev Psychiatry 2003; 15: 150-2.

5. Mumola CJ, Karberg JC. Drug use and dependence, state and federal prisoners, 2004. Washington, DC: Bureau of Justice Statistics; 2006.

6. Fisher W, Roy-Bujnowski K, Grudzinskas A, Clayfield J, Banks S, Wolff N. Patterns and prevalence of arrest in a statewide cohort of mental health care consumers. Psychiatr Serv 2006; 57: 1623-8. doi: 10.1176/appi.ps.57.11.1623.
7. Lamb HR, Grant RW. The mentally ill in an urban county jail. Arch Gen Psychiatry 1982; 39: 17-22.

8. Fazel S, Bains P, Doll H. Substance abuse and dependence in prisoners: a systematic review. Addiction 2006; 101: 181-91.

9. Friestad C, Kjelsberg E. Drug use and mental health problems among prison inmates - results from a nation-wide prison population study. Nord J Psychiatry 2009; 63: 237-45.

10. Birmingham L, Mullee M. Development and evaluation of a screening tool for identifying prisoners with severe mental illness. Psychiatr Bull 2005; 29: 334-8.

11. Humphreys M. Aspects of basic management of offenders with mental disorders. Adv Psychiatr Treat 2000; 6: 22-30. doi: 10.1192/apt.6.1.22.

12. Assadi S, Noroozian M, Pakravannejad M. Psychiatric morbidity among sentenced prisoners: prevalence study in Iran. Br J Psychiatry 2006; 188: $159-64$

13. Shaw J, Humber N. Prison mental health services. Psychiatry 2004; 3: $21-4$.

Submitted 13 Oct 2014

Accepted 27 Oct 2014

Published 16 Mar 2015

Online: http://www.mona.uwi.edu/wimjopen/article/1619

(C) Sewell et al 2015

This is an open access article made freely available under Creative Commons Attribution 4.0 International (CC BY 4.0). Users are free to share, copy and adapt this work as long as the copyright holder (author) is appropriately and correctly credited. See http:// creativecommons.org/licences/by/4.0/deed.en_us for more information. 